\title{
Pengaruh Parameter Pemotongan Pada Proses Bubut Ulir (Threading) Terhadap Kepresisian Geometri Ulir Magnesium Paduan AZ31
}

\author{
Gusri Akhyar Ibrahim ${ }^{1)^{*}}$, Alan Suseno ${ }^{1)}$, Arinal Hamni ${ }^{1}$ \\ ${ }^{1)}$ Fakultas Teknik, Universitas Lampung, Kota Bandar Lampung, Lampung \\ Naskah diterima 06/02/2019; direvisi 01/04/2019; disetujui 22/04/2019 \\ doi: https://doi.org/10.24843/JEM.2019.v12.i01.p01
}

\begin{abstract}
Abstrak
Magnesium telah dikembangkan dalam bidang kedokteran yaitu sebagai material untuk implan dalam tubuh. Hasil penelitian sebelumnya menunjukan bahwa faktor utamanya adalah sifat magnesium sangat mirip dengan sifat tulang manusia. Sekrup AZ31 menunjukkan kekuatan tarik keluar yang serupa dengan sekrup stainless steel saat ditarik dari bahan tulang sintetis, dan tingkat degradasi jenis sekrup Mg-alloy di ruang tulang sumsum dan otot lebih cepat daripada di ruang tulang kortikal. Hal ini menunjukan bahwa pembuatan ulir pada magnesium AZ31 sangat mendukung untuk diaplikasikan pada bidang material biomedic. Kepresisian geometri ulir akan memberikan pengaruh terhadap kwalitas ulir, terutama pada saat ulir bekerja bila sudah digunakan sebagai penyambung tulang. Untuk mengatasi masalah tersebut, dapat dilakukan variasi pada parameter proses pemesinan magnesium, yaitu parameter pemotongan pada saat pembubutan ulir untuk mendapatkan hasil yang paling baik akurasinya. Hasil penelitian menunjukan nilai kesalahan tinggi ulir minimum yaitu 0,018188 mm didapatkan pada parameter kecepatan spindel $424 \mathrm{rpm}$ dan kedalaman potong 0,433015. Nilai kesalahan jarak puncak ulir (pitch) minimum yaitu $0,0205 \mathrm{~mm}$ didapatkan pada parameter kecepatan spindel $212 \mathrm{rpm}$ dan kedalaman potong 0,649523 mm. Nilai kesalahan sudut minimum yaitu 0,603 didapatkan pada parameter kecepatan spindel $212 \mathrm{rpm}$ dan kedalaman potong 0,324761 mm.
\end{abstract}

Kata kunci : threading, akurasi, geometri, magnesium, AZ31

\begin{abstract}
Magnesium has been developed in the field of medic as a material for implants. The results of previous studies show that the main factor is the characteristic of magnesium very similar to the characteristic of human bones. AZ31 screws show outward tensile strength similar to stainless steel screws when pulled from synthetic bone material, and the degradation rate of Mg-alloy screw types in the marrow and muscle bone space is faster than in cortical bone space. This shows that the screw making on magnesium AZ31 is very possible to be applied in the biomedical material field. The precision of the screw geometry will have an effect on the quality of the thread, especially when the screw works when it has been used as a bone joint. To overcome this problem, variations in the machining process parameters are carried out, the cutting parameters at the time of screw turning to get the best accuracy results. The results showed that the minimum screw depth error value is $0.018188 \mathrm{~mm}$, obtained at the spindle speed parameter of $424 \mathrm{rpm}$ and depth of cut $0.433015 \mathrm{~mm}$. The minimum pitch error value is $0.0205 \mathrm{~mm}$ obtained on the parameters of the spindle speed of $212 \mathrm{rpm}$ and depth of cut $0.649523 \mathrm{~mm}$. The minimum angle error value is $0.603{ }^{\circ}$ obtained in the parameters of the spindle speed $212 \mathrm{rpm}$ and the depth of cut $0.324761 \mathrm{~mm}$.
\end{abstract}

Keywords: threading, accuracy, geometry, magnesium, AZ31

\section{Pendahuluan}

Magnesium merupakan material dengan unsur kedelapan terbanyak yang ada di permukaan bumi, yaitu sekitar $2 \%$ dari berat kerak bumi. Selain itu juga magnesium adalah unsur paling banyak ketiga yang terlarut dalam air laut [8]. Dapat dipastikan bahwa magnesium adalah sumber daya alam yang melimpah di bumi ini dan harus dimanfaatkan dengan optimal untuk kemajuan teknologi. Karena sifatnya dan kesetersediannya relatif banyak maka pengembangan penggunaan material magnesium dilakukan secara berkerusan.

Magnesium sendiri hanya memiliki kepadatan setara dengan dua pertiga kali dari alumunium. Karena kepadatannya yang lebih rendah dari alumunium, maka magnesium banyak diaplikasikan pada komponen maupun konstruksi yang membutuhkan material yang ringan. Magnesium juga telah dikembangkan secara besar-besaran dalam bidang kedokteran yaitu sebagai material untuk implan, material yang mengantikan tulang dan dimasukan ke dalam tubuh manusia. Faktor utama yang mendorong magnesium dikembangkan pada bidangn ini adalah karena sifat magnesium sangat mirip dengan sifat tulang manusia. Selain sifatnya yang hampir sama, magnesium juga memiliki biocompatible yang baik serta luluh di dalam tubuh [5].Tingkat degradasi kedua jenis sekrup Mg-alloy di ruang tulang sumsum dan otot lebih cepat daripada di ruang tulang kortikal [2].

Dalam bidang biomedic, ulir sudah menjadi sebuah komponen yang sangat penting sebagai implant tulang. Hal ini menunjukan bahwa pembuatan ulir pada magnesium AZ31 sangat mendukung untuk diaplikasikan pada bidang material biomedic. Bagaimanapun juga sudah ada beberapa penelitian mengenai sekrup dan ulir menggunakan material 
magnesium paduan $A Z 31$, tetapi belum ada yang membahas tentang pengaruh parameter pemotongan terhadap kepresisian geometri ulirnya. Kepresisian geometri ulir akan memberikan pengaruh terhadap kwalitas ulir, terutama pada saat ulir bekerja bila sudah digunakan sebagai penyambung tulang. Pada penelitian ini akan dilakukan pembuatan ulir metrik M22x1,5 dengan menggunakan material magnesium paduan AZ31 dengan parameter yang digunakan adalah kecepatan spindel sebesar 212, 318 dan 424 rpm. Kondisi ini dipertimbangkan karena mengacu pada penelitian Viswanathan [9], Ialu mengacu pada standar isometrik, tinggi ulir untuk M22×1,5 adalah 1,299045 mm. Dengan demikian maka kedalaman potong yang divariasikan adalah sebesar 0,324761 $\mathrm{mm}$., 0,433015 dan 0,649523 mm

\section{Metode Penelitian}

Benda kerja yang digunakan pada penelitian ini adalah magnesium paduan AZ31 dengan komposisi kimia yang utamanya yaitu $A l=3 \% \quad Z n=1 \%$ dan sisanya Mg. Pemesinan bubut ulir (threading) dilakukan menggunakan mesin CNC tipe Focus NXL300. Pahat potong yang digunakan yaitu jenis pahat potong dengan tipe insert ulir 16ER AG60 yang berbahan High Speed Steel (HSS). Pemilihan bahan pahat HSS, disebabkan karena benda kerja yang dipotong adalah paduang magnesium, dimana bahan ini memiliki sifat tidak keras dan suhu pemotongan rendah. Dengan demikian, penggunaan jenis pahat HSS sesuai bila digunakan untuk pemotongan bahan magnesium paduan.
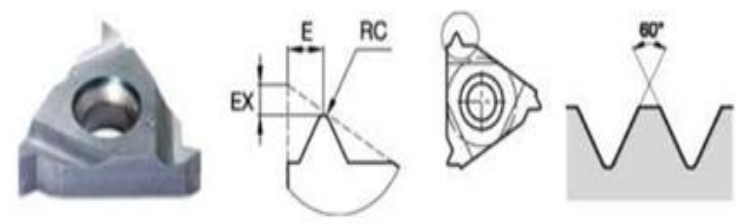

\begin{tabular}{cccccc}
\hline $\begin{array}{c}\text { No. } \\
\text { Katalog }\end{array}$ & RC & EX & E & $\begin{array}{c}\text { Ukuran } \\
\text { insert }\end{array}$ & $\begin{array}{c}\text { Ukuran } \\
\text { pitch }\end{array}$ \\
\hline $\begin{array}{c}\text { 16ER } \\
\text { AG60 }\end{array}$ & 0,08 & 1,2 & 1,7 & 3 & $0,50-3,0$
\end{tabular}

Gambar 1. Dimensi mata pahat ulir [2]

Benda kerja dibentuk menjadi silinder dengan diameter sebesar $22 \mathrm{~mm}$ setelah itu dilakukan pemesinan threading atau ulir dengan standar metrik M22x1,5. Variasi kecepatan spindel yang digunakan sebesar 212, 318 dan $424 \mathrm{rpm}$ dan kedalaman potong sebesar 0,324761 mm, 0,433015 mm dan 0,649523 $\mathrm{mm}$. Pemilihan parameter didasarkan pada pertimbangan dari penelitian sebelumnya, jenis bahan yang dipotong, jenis pahat yang digunakan dan jenis pemotongan tampa menggunakan pelumas atau pendingin [4].

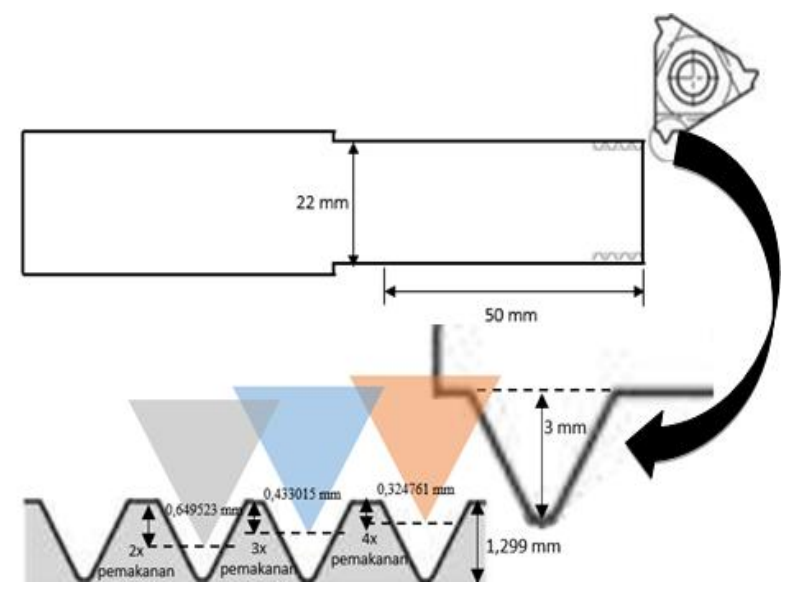

Gambar 2. Dimensi pahat dan kedalaman potong yang digunakan

Pengukuran dimensi ulir menggunakan profil projector Multytuyo dengan pembesaran 20x. Pengukuran dilakukan secara manual dengan meletakan benda kerja dihadapan projektor, sehingga akan terlihat bayangan tinggi puncak, sudur dan nilai bacaan dimensinya. Data yang diambil sewaktu pengujian adalah diameter mayor, diamemeter minor, komulatif jarak, dan kesalahan sudut ulir. Secara detail, data hasil pengukuran ditabel dengan struktur sebagaimana yang ditunjukkan pada pada Tabel 1.

Tabel 1. Data pengukuran ulir

\begin{tabular}{|l|l|l|l|l|l|l}
\hline \multicolumn{2}{l|}{ Pembesaran: } & \multicolumn{4}{l|}{$\begin{array}{l}\text { Kecermatan profil } \\
\text { projector }\end{array}$} & \multicolumn{3}{l}{ Jarak pits teoritik: } \\
\hline $\begin{array}{l}\text { Pengukuran } \\
\text { ke }\end{array}$ & $\begin{array}{l}\text { Diameter } \\
\text { mayor }\end{array}$ & $\begin{array}{l}\text { Diameter } \\
\text { minor }\end{array}$ & $\begin{array}{l}\text { Komulatif } \\
\text { jarak pits }\end{array}$ & $\begin{array}{l}\text { Komulatif } \\
\text { hasil } \\
\text { pengukuran } \\
\text { pits (mm) }\end{array}$ & $\begin{array}{l}\text { Kesalahan } \\
\text { sudut ulir }\end{array}$ & $\begin{array}{l}\text { Kesalahan } \\
\text { pitch } \\
\text { (mm) }\end{array}$ \\
\hline 1 & & & & & & \\
\hline 2 & & & & & & \\
\hline dst & & & & & & \\
\hline \multicolumn{7}{|l|}{ Kesalahan rata-rata }
\end{tabular}

Metode pengolahan data menggunakan metode full factorial dimana setiap kombinasi dari dari variasi parameter pemotongan akan diamati sebagaimana yang ditunjukan pada Tabel 2. Setelah semua nilai kesalahan dimensi ulir ditentukan, setiap benda kerja dilihat kerusakan permukaannya menggunakan mikroskop USB dan dianalisa jenis kerusakan apa saja yang ditemukan pada profil permukaan ulir. Hal ini lakukan untuk memprediksi jenis kerusakah yang terjadi dan dikaitkan dengan tingkat parameter yang digunakan.

\section{Hasil dan Pembahasan}

Data hasil pengujian yang didapatkan dari proses pemesinan ulir atau threading dengan berbagai variasi parameter pemotongan, dihasilkan data yang beragam seperti ditunjukkan pada Tabel 2. Kecepatan spindel ditentukan, kemudian nilai pengukuran kedalaman potong, kesalahan ulir, kesalahan puncak dan 
kesalahan sudut analisa menggunakan kecenderangan pada grafik. Sehingga dapat diamati pengaruh kedalaman potong terhadap tingkat kesalahan tinggi ulir, kesalahan sudut ulir dan kesalahan puncak ulir.

Tabel 2 Data hasil pengukuran dimensi ulir pada pengaruh kedalaman potong.

\begin{tabular}{|c|c|c|c|c|c|}
\hline No & $\begin{array}{c}\text { Putaran } \\
\text { spindel } \\
(\mathrm{rpm})\end{array}$ & $\begin{array}{c}\text { Kedalaman } \\
\text { potong } \\
(\mathrm{mm})\end{array}$ & $\begin{array}{c}\text { Kesalahan } \\
\text { Tinggi Ulir } \\
(\mathrm{mm})\end{array}$ & $\begin{array}{l}\text { Kesalahan } \\
\text { Pich (mm) }\end{array}$ & $\begin{array}{l}\text { Kesalahan } \\
\text { Sudut }\left({ }^{\circ}\right)\end{array}$ \\
\hline 1 & \multirow{3}{*}{212} & 0,324761 & 0,041845 & 0,0337 & 0,603 \\
\hline 2 & & 0,433015 & 0,032842 & 0,0299 & 1,566 \\
\hline 3 & & 0,649523 & 0,054264 & 0,0205 & 1,66 \\
\hline 4 & \multirow{3}{*}{318} & 0,324761 & 0,040095 & 0,0446 & 0,793 \\
\hline 5 & & 0,433015 & 0,031945 & 0,04 & 1,718 \\
\hline 6 & & 0,649523 & 0,054014 & 0,0281 & 1,832 \\
\hline 7 & \multirow{3}{*}{424} & 0,324761 & 0,030245 & 0,0512 & 0,93 \\
\hline 8 & & 0,433015 & 0,018118 & 0,0447 & 1,796 \\
\hline 9 & & 0,649523 & 0,041905 & 0,0312 & 1,886 \\
\hline
\end{tabular}

\subsection{Pengaruh kedalaman potong terhadap kesalahan tinggi ulir}

Dari Tabel 2 dapat diketahui bahwa parameter kedalaman potong mempengaruhi terhadap tingkat salah kesalahan pada pembuatan ulir. Tingkat kesalahan tinggi ulir dapat diamati pada tabel, akan tetapi untuk lebih detail dan mudah memberikan penjelasan maka data tabel diterjemahkan ke dalam grafik, sebagaimana yang ditunjukkan pada Gambar 3.

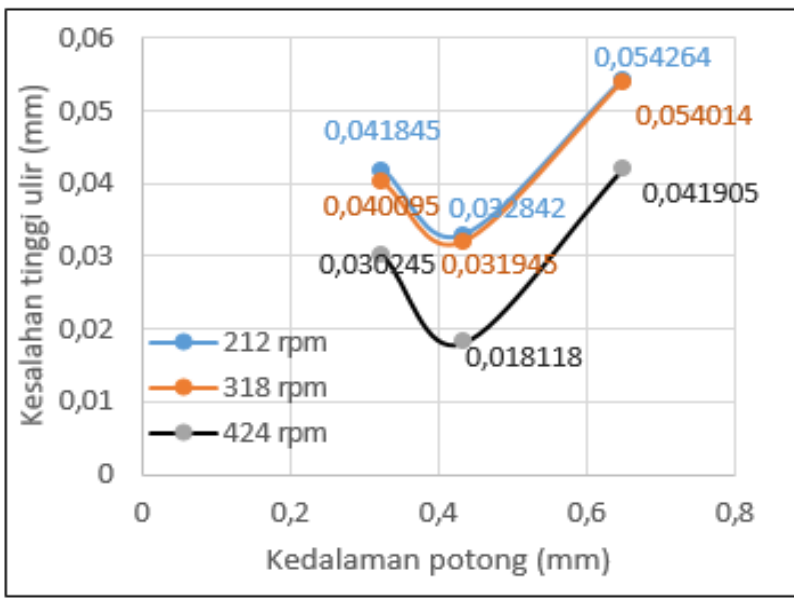

Gambar 3. Grafik Pengaruh kedalaman potong terhadap kesalahan tinggi puncak ulir

Grafik pada Gambar 3 di atas membuktikan bahwa kedalaman potong mempengaruhi kesalahan pada tinggi puncak ulir. Pada masing-masing kecepatan spindel titik terendah terdapat pada kedalaman potong $0,433015 \mathrm{~mm}$. Ssedangkan nilai kesalahan tinggi puncak ulir terkecil yaitu 0,018118 $\mathrm{mm}$ atau $1,39 \%$ terdapat pada kecepatan spindel (n) $424 \mathrm{rpm}$ dengan kedalaman potong sebesar (a) $0,433015 \mathrm{~mm}$. Dan nilai kesalahan tinggi puncak ulir terbesar yaitu $0,054264 \mathrm{~mm}$ atau $4,17 \%$ terdapat pada $\mathrm{n}=212 \mathrm{rpm}$ dan $\mathrm{a}=0,649523 \mathrm{~mm}$. Dimana toleransi tinggi untuk standar metrik dengan jarak pitch 1,5 adalah $0,1 \mathrm{~mm}$ untuk penyimpangan sedang dan 0,05 $\mathrm{mm}$ untuk penyimpangan halus

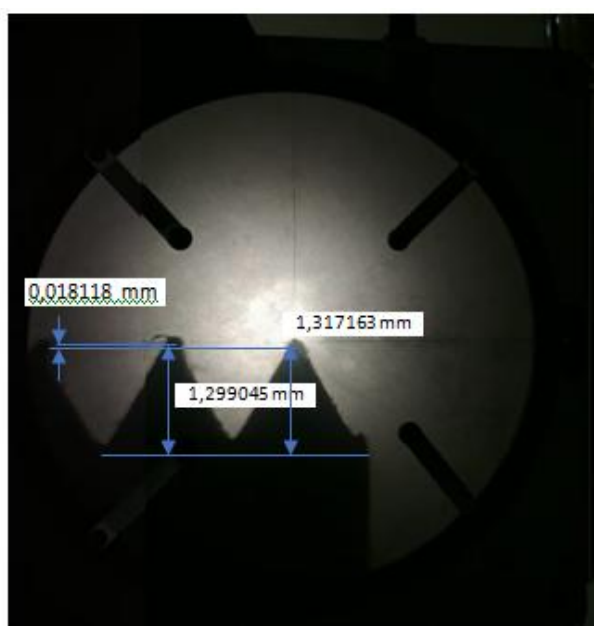

Gambar 4. Penyimpangan geometri tinggi puncak ulir pada kecepatan spindel $424 \mathrm{Rpm}$ dengan kedalaman potong sebesar $0,433015 \mathrm{~mm}$

Kasus seperti ini juga pernah ditemui oleh Agung pada tahun 2016 pada penelitiannya yang meneliti kepresisian geometri ulir pada baja karbon rendah. Menurutnya hal ini terjadi karena pengaruh gaya pemotongan yang searah kecepatan potong $\left(f_{v}\right)$ dan gaya pemotongan searah kecepatan pemakanan $\left(f_{f}\right)$ [1]. Namun pada penelitian tersebut tidak dijabarkan tentang kolerasi antara kedalaman potong terhadap gaya potongnya, sehingga belum ada kesimpulan yang didukung oleh penjelasan data hasil penelitian. Pada penelitian ini kedalaman potong yang baik digunakan adalah kedalaman potong sebesar $0,433015 \mathrm{~mm}$. Akan tetapi keadaan ini berlaku pada rentang kedalaman potong yang terbatas. Dengan pemilihan kedalaman potong yang besar, kestabilan mata potong pahat lebih tinggi sehingga permukaan hasil pemotongan lebih seragam. Dengan demikian, tingkat kesalahan permukaan yang diukur lebih kecil.

\subsection{Pengaruh kedalaman potong terhadap kesalahan sudut ulir}

Kesalahan sudut ulir secara logis dapat dipengaruhi oleh kedalaman potong dan gerak makan saat proses pemesinan. Hal ini disebabkan karena kedalaman potong berhubungan langsung dengan gaya pemotongan, sehingga energi pemotongan yang diperlukan juga bergantung pada daya pemotongan. Hasil pengujian pengaruh kedalaman potong terhadap kesalahan sudut ulir dapat dilihat pada Gambar 5 berikut. 


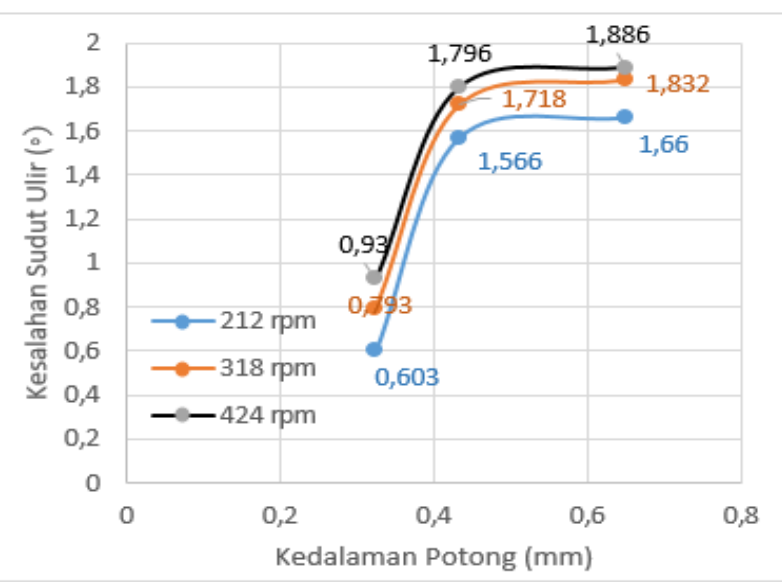

Gambar 5. Grafik pengaruh kedalaman potong terhadap kesalahan sudut ulir

Dapat dilihat pada Gambar 5 bahwa nilai kesalahan sudut ulir terkecil yaitu $0,603^{\circ}$ didapatkan pada keadaan nilai $\mathrm{a}=0,324761 \mathrm{~mm}$ dan $\mathrm{n}=212$ rpm. Sedangkan nilai kesalahan sudut ulir terbesar yaitu $1,886^{\circ}$ didapatkan pada $a=0,649523 \mathrm{~mm}$ dan $\mathrm{n}$ $=424 \mathrm{rpm}$.

Jika dilihat kembali bahwa dari nilai $0,324761 \mathrm{~mm}$ ke $0,433015 \mathrm{~mm}$ tingkat penyimpangan sudut terlihat meningkat cukup tinggi yaitu dari $1,005 \%$ ke 2,61\%. Setelah kedalaman ditingkatkan dari $0,433015 \mathrm{~mm}$ ke $0,649523 \mathrm{~mm}$ maka tingkat penyimpangan sudut ulir juga meningkat, akan tetapi tidak terlalu tinggi yaitu hanya sebesar dari 2,61 \% ke 2,7\%. Hal ini disebabkan karena kesalahan sudut ulir yang sudah mendekati nilai maksimal. Dengan demikian, tingkat kesalahan ulir yang dihasilkan tidak bisa lagi meningkat. Penyebabnya adalah dimensi dari ulir yang dibuat yaitu memiliki tinggi $1,299045 \mathrm{~mm}$, dengan kedalaman potong $0,433015 \mathrm{~mm}$ dan $0,649523 \mathrm{~mm}$ dimana jumlah pengulangan pemotongannya adalah 3 kali dan 2 kali. Maka kontak mata pahat yang bersentuhan dengan permukaan benda kerja akan semakin luas sehingga kesalahan sudut ulir dapat mendekati keadaan maksimalnya. Penyimpangan sudut ulir dapat dilihat pada Gambar 6 dimana kesalahan sudutnya sebesar $0,603^{\circ}$

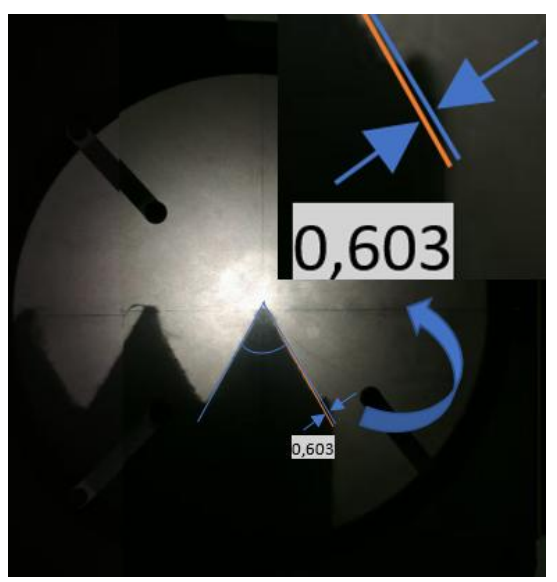

Gambar 6. Penyimpangan geometri sudut ulir pada kedalaman potong $0,324761 \mathrm{~mm}$ dan kecepatan spindel 212 rpm

\subsection{Pengaruh kedalaman potong terhadap kesalahan jarak puncak ulir (pitch)}

Jarak puncak ulir (pitch) ke puncak ulir lainnya merupakan bagian yang paling penting dalam elemen mur dan baut. Dalam hasil yang telah didapatkan keseluruhan data menunjukan bahwa jarak antar pitch masih dalam toleransi ulir standar M22x1,5 yaitu 0,1 $\mathrm{mm}$. Berikut adalah grafik hasil pengujian yang menentukan tingkat kesalahan ulir bila ditinjau dari keadaan kedalaman potong yang berbeda-beda. Secara detail tingkat kesalahannya dapat diamati pada Gambar 7.

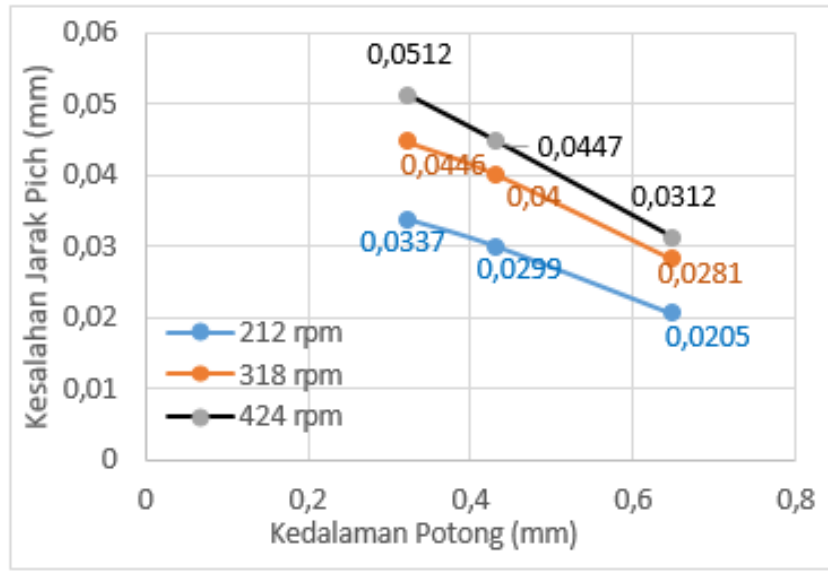

Gambar 7. Grafik pengaruh kedalaman potong terhadap kesalahan jarak puncak ulir (pitch)

Dari grafik di atas dapat dilihat bahwa kesalahan jarak puncak ulir terkecil sebesar 0,0205 mm terdapat pada kedalaman potong $0,649523 \mathrm{~mm}$ dan kecepatan spindel $212 \mathrm{rpm}$, sedangkan. kesalahan jarak puncak ulir terbesar yaitu $0,0512 \mathrm{~mm}$ terdapat pada kedalaman potong $0,324761 \mathrm{~mm}$ dan kecepatan spindel $424 \mathrm{rpm}$. Sedangkan toleransi pitch yang dibolehkan untuk standar metrik dengan jarak pitch 1,5 adalah $0,1 \mathrm{~mm}$ untuk penyimpangan sedang dan 0,05 $\mathrm{mm}$ untuk penyimpangan halus. Dengan demikian dapat dikatakan bahwa tingkat kesalahan yang dihasilkan masih dapat diterima karena angka kesalahannya lebih kecil daripada nilai standarnya.

Dengan demikian pada penelitian ini didapatkan kesimpulan sementara bahwa semakin besar kedalaman potong yang diimplementasikan pada pemesinan drill material paduan magnesium maka semakin kecil kesalahan jarak antar puncak ulir yang dihasilkan. Besarnya kesalahan puncak yang dihasilkan, salah satunya adalah sebagaimana yang ditunjukkan pada Gambar 8. 


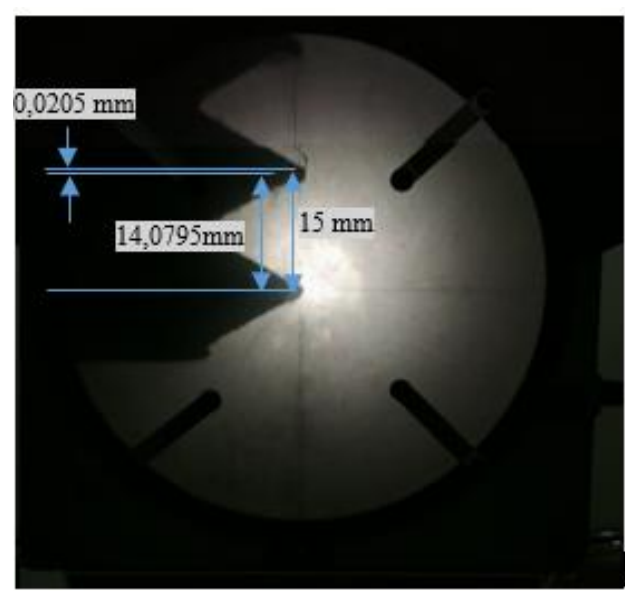

Gambar 8. Kesalahan jarak puncak ulir terkecil pada kedalaman potong $0,649523 \mathrm{~mm}$ dan kecepatan spindel $212 \mathrm{rpm}$

\subsection{Pengaruh kedalaman potong pada bentuk profil permukaan ulir magnesium paduan AZ31}

Mengacu kepada data yang ditampilkan pada Tabel 1 bahwa tabel tersebut dapat digunakan sebagai pembanding dengan nomor urut penelitian yang sudah ditentukan. Pada nomor urut pengujian 1,2 dan 3 menggunakan kecepatan spindel yang sama yaitu 212 rpm, sedangkan kedalaman potong yang berbedabeda. Gambar 3 menunjukan fenomena yang berbeda antara 1, 2 dan 3. Permukaan benda kerja yang dipotong menunjukan adanya bentuk profil yang kasar dan halus. Hal ini menunjukan bahwa kedalaman potong memberikan pengaruh terhadap keadaan permukaan yang di mesin. Sebagaimana diketahui bahwa material paduan magnesium adalah material lunak, sehingga mudah mengalami perubahan atau deformasi pada suhu yang relatif tinggi.

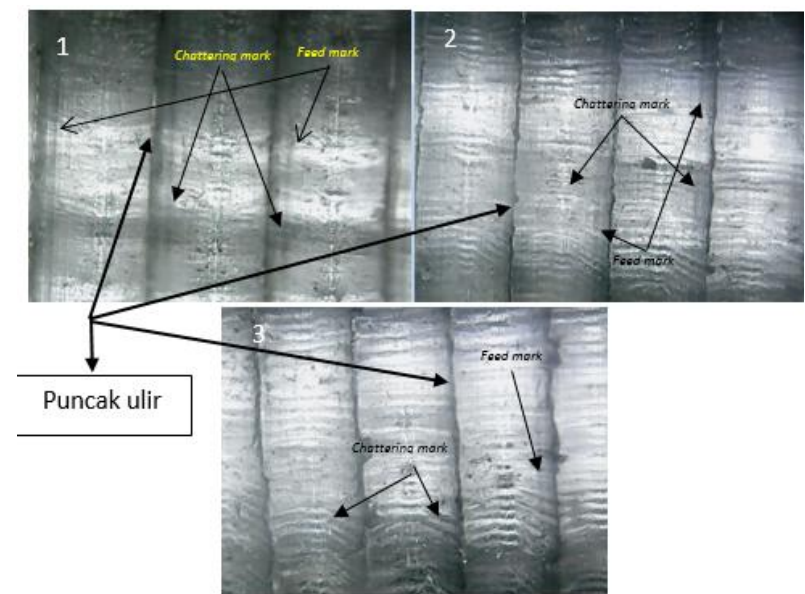

Gambar 12. Bentuk profil permukaan ulir magnesium paduan AZ31 pada kecepatan spindel 212 rpm (1) kedalaman potong $0,324761 \mathrm{~mm}$ (2) kedalaman potong $0,433015 \mathrm{~mm}$ (3) kedalaman potong 0,649523 $\mathrm{mm}$

Dari ketiga pengujian tersebut dapat diidentifikasi dua pola yang terjadi pada permukaan benda kerja yaitu chattering mark dan feed mark. Chattering merupakan fenomena yang terjadi selama proses pemesinan berlangsung dimana beberapa jenis getaran mempengaruhi laju aliran geram (chip) dan permukaan benda kerja. Dibandingkan dengan getaran bebas dan getaran paksa, Self-Excited Vibration lebih merugikan permukaan benda kerja dan pahat yang digunakan karena menimbulkan gerakan amplitudo yang relatif besar antara pahat dan benda kerja. Chatter tersebut disebabkan oleh kedalaman potong yang terlalu dalam pada proses pemesinan. Sedangkan feed mark menggambarkan kedalaman potong pada ulir, kedalaman potong yang besar akan menghasilkan feed mark yang lebih kasar [3].

\section{Simpulan}

Adapun kesimpulan yang didapat dari penelitian ini adalah sebagai berikut:

1. Nilai kesalahan tinggi ulir minimum yaitu 0,018188 $\mathrm{mm}$ didapatkan pada parameter kecepatan spindel $424 \mathrm{rpm}$ dan kedalaman potong $0,46 \mathrm{~mm}$ dan semakin tinggi kecepatan spindel maka semakin rendah nilai kesalahan ulir.

2. Nilai kesalahan jarak puncak ulir (pich) minimum yaitu $0,0205 \mathrm{~mm}$ didapatkan pada parameter kecepatan spindel $212 \mathrm{rpm}$ dan kedalaman potong $0,6133 \mathrm{~mm}$, semakin tinggi nilai kedalaman potong maka semakin rendah nilai kesalahan pich.

3. Nilai kesalahan sudut minimum yaitu $0,603^{\circ}$ didapatkan pada parameter kecepatan spindel 212 rpm dan kedalaman potong $0,31 \mathrm{~mm}$, semakin tinggi nilai kedalaman potong maka semakin tinggi nilai kesalahan sudut ulir

4. Bentuk profil permukaan ulir terbaik yaitu dengan sedikit chattering mark dan feed mark didapatkan pada parameter kecepatan spindel $424 \mathrm{rpm}$ dan kedalaman potong $0,31 \mathrm{~mm}$, semakin tinggi nilai kedalaman potong maka semakin kasar bentuk profil permukaan ulir,

\section{Ucapan Terima Kasih}

Ucapan terima kasih disampaikan kepada Lembaga Penelitian dan Pengabdian Universitas Lampung yang telah menfasilitasi terlaksananya penelitian ini. Ucapan terima juga disampaikan kepada Kementerian Riset, Teknologi dan Pendidikan Tinggi yang telah memberikan support finansial untuk kelancaran kegiatan penelitian.

\section{Daftar Pustaka}

[1]. Agung, Mochammad. 2016. Pengaruh Kecepatan Potong Terhadap Kepresisian Geometri Ulir standar ISO Metrik dengan Menggunakan Baja S45C pada Mesin CNC ET242. Jurusan Teknik Mesin Fakultas Teknik Universitas Brawijaya. Malang

[2]. Henderson Sarah E, Konstantinos Verdelis, Spandan Maiti, Siladitya Pal, William L. Chung, Da-Tren Chou, Prashant N. Kumta, dan Alejandro 
J. Almarza. 2014. Magnesium Alloys as a Biomaterial for Degradable Craniofacial Screws. Acta Materialia Inc : Pittsburgh

[3]. Hamdan, Siti H., Said, A.Y.Md., Biki, R. 2015. Surface Finishing when Threading TitaniumBased Alloy Under Dry Machining. Journal of Machining Engineering and Sciences Vol. Pp. 1062-1069

[4]. Ibrahim, G.A. 2014. Analisa Kekasaran Permukaan pada Pemesinan Paduan Magnesium. Jurusan Teknik Mesin. Universitas Lampung. Bandar Lampung.

[5]. J. Bai, L. Yin, Y. Lu, Y. Gan, F. Xue, C. Chu, J, Yan, K. Yan, X. Wan, Z. Tang. 2014. Preparation, microstructure and degradation performance of biomedical magnesium alloy fine wire, Natural Science: Material International 24

[6]. Kalpakjian, S. 1995. Manufacturing Process for Engineering and Technology. 3th Edition, Addison Wesley Publishing Company.

[7]. Liwei Lu, Shaohua Hu, Longfei Liu, Zhenru Yin. 2016. High speed cutting of AZ31 magnesium alloy. Elsevier B.V. on behalf of Chongqing University : Hunan

[8]. Saputra, Robby. 2017. Kekasaran Permukaan Magnesium AZ31 Yang Difrais Menggunakan Teknik Pelumasan Berkuantitas Minimum (MQL). Jurusan Teknik Mesin. Universitas Lampung. Bandar Lampung.

[9]. Viswanathan, R dan Ramesh, S. 2014. Optimization of Machining Parameters for Magnesium Alloy using Taguchi Approach and RSM. Dept. International Conferences on Advances in Design and Manufacturing 